WellBeing International

WBI Studies Repository

$12-2015$

\title{
Autonomic Nervous System Reactivity in a Free-Ranging \\ Mammal: Effects of Dominance Rank and Personality
}

\author{
Elodie F. Briefer \\ Queen Mary University of London \\ James A. Oxley \\ Queen Mary University of London \\ Alan G. McElligott \\ Queen Mary University of London
}

Follow this and additional works at: https://www.wellbeingintlstudiesrepository.org/acwp_ena

Part of the Animal Studies Commons, Other Animal Sciences Commons, and the Veterinary

Physiology Commons

\section{Recommended Citation}

Briefer, E. F., Oxley, J. A., \& McElligott, A. G. (2015). Autonomic nervous system reactivity in a free-ranging mammal: effects of dominance rank and personality. Animal Behaviour, 110, 121-132.

This material is brought to you for free and open access by WellBeing International. It has been accepted for inclusion by an authorized administrator of the WBI Studies Repository. For more information, please contact wbisr-info@wellbeingintl.org.

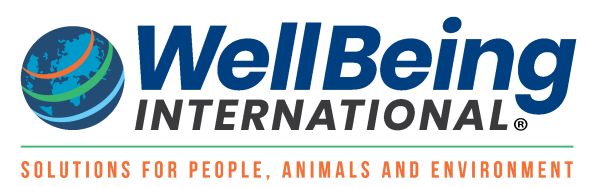




\title{
Autonomic Nervous System Reactivity in a Free- Ranging Mammal: Effects of Dominance Rank and Personality
}

\author{
Elodie F. Briefer ${ }^{\dagger}$, James A. Oxley, Alan G. McElligott ${ }^{\dagger}$ \\ ${ }^{\dagger}$ Queen Mary University of London
}

\section{$\underline{\text { KEYWORDS }}$}

Avoidance, behavior, goats, heart rate, hierarchy, RMSSD, sociability

\begin{abstract}
$\underline{\text { ABSTRACT }}$
Modulation of the autonomic nervous system (ANS) activity allows animals to effectively respond to internal and external stimuli in everyday challenges via changes in, for example, heart and respiration rate. Various factors, ranging from social such as dominance rank to internal such as personality or affective states can impact animal physiology. Our knowledge of the combinatory effects of social and internal factors on ANS basal activity and reactivity, and of the importance that each factor has in determining physiological parameters, is limited, particularly in nonhuman, free-ranging animals. In this study, we tested the effects of dominance rank and personality (assessed as exploration/avoidance and sociability) on the heart rate (HR) and heart rate variability of goats, Capra hircus, in relation to the category of behaviour performed. We collected heart rate data while the animals could freely move and interact with conspecifics. A model selection procedure showed that behavioural category and sociability, as well as their interaction effect, explained most of the variation in HR. HR was lowest, and heart rate variability highest, during affiliative interactions. The HR of less social goats increased more between the behaviour triggering the lowest $H R$ and the behaviour triggering the highest $H R$, compared to the $H R$ of more social goats, which was more stable. This suggests lower ANS reactivity (HR response) in social goats. Our results thus highlight the important relationships between personality types, physiology and the behaviour of free-ranging animals.
\end{abstract}

The autonomic nervous system (ANS) regulates heart rate and other physiological parameters (e.g. respiration rate, skin temperature). Its main function is to enable individuals to respond to changes in their environment and thus deal with everyday challenges by regulating energy expenditure through normal physiological fluctuations (i.e. Seyle, 1976). Additionally, the ANS plays a crucial role in the control of the 
neuronal or 'fight-or-flight' stress response, which prepares the animal to immediately react to internal and external stimuli perceived as threatening (Koolhaas et al., 2011). ANS basal activity (i.e. activity at rest) is related to factors that are fixed over the life of an individual such as species, sex or breed (Hezzell, Humm, Dennis, Agee, \& Boswood, 2013; Lillywhite, Zippel, \& Farrell, 1999), to factors that are subjected to slow changes over time such as body size or age (Noujaim et al., 2004; Stahl, 1967), or to daily changes (circadian rhythms; MacArthur, Johnston, \& Geist, 1979). Furthermore, there is some evidence to suggest that both ANS activity and reactivity (i.e. increase from baseline levels in response to an environmental stimulus; Matthews, 1986) can be related to social factors such as dominance rank (Aschwanden, Gygax, Wechsler, \& Keil, 2008; Sapolsky, 2005; Turbill, Ruf, Rothmann, \& Arnold, 2013), or to internal factors such as personality (Koolhaas et al., 1999; Réale et al., 2010). On a daily basis, rapid changes in physiology can occur according to external factors such as ambient temperature (Baldock, Sibly, \& Penning, 1988), to internal factors such as affective states (Briefer, Tettamanti, \& McElligott, 2015) or to the physiological activity involved in each behaviour performed (Major, 1998).

Dominance rank influences both ANS basal activity (e.g. Turbill et al., 2013) and reactivity (Creel, 2001), in primates (Abbott et al., 2003), but also in other species (e.g. geese, Anser anser; Kralj-Fišer, Weiß, \& Kotrschal, 2010), and this can affect disease susceptibility and even fertility and survival (Sapolsky, 2005). The stress experienced by individuals at various levels of the dominance hierarchy seems to depend on the social structure of a species (e.g. the degree to which they are exposed to social stressors and the degree of available social support; Abbott et al., 2003; Creel, Dantzer, Goymann, \& Rubenstein, 2013). Therefore, low-ranking individuals could have lower or higher stress levels than high-ranking ones depending on the species or context. The effect of dominance on physiological parameters appears complex and has produced mixed results in farm animals (e.g. for goats, Capra hircus, see Aschwanden et al., 2008; Miranda-de la Lama et al., 2013).

Animal personality (Gosling, 2001; or temperament; Réale, Reader, Sol, McDougall, \& Dingemanse, 2007; or coping style; Koolhaas et al., 1999) is defined as individual behavioural differences that are repeatable over time and across situations (Réale et al., 2007). The relationship between personality and ANS reactivity has mainly been studied through coping strategies. Two main coping strategies that are revealed when the stress threshold is reached have been highlighted in animals (Koolhaas et al., 1999). When stressed, proactive individuals typically react by escaping or removing the stressor (fight-or-flight response), while reactive individuals display a conservation--withdrawal response (i.e. behavioural immobility and low level of aggression). Proactive individuals are also more likely to be aggressive, explore faster and be neophilic (i.e. novelty seekers) than reactive ones (Koolhaas, de Boer, Coppens, \& Buwalda, 2010; Steimer \& Driscoll, 2003). In addition to behavioural differences, these two coping styles are characterized by differences in their physiology: reactive individuals have lower sympathetic reactivity (i.e. lower heart rate response) and higher parasympathetic reactivity (i.e. bradycardia response; lower heart rate response and higher heart rate variability) than proactive ones (Koolhaas, 2008). These differences are adaptive as they confer differential fitness depending on the environmental conditions. Indeed, proactive individuals are better adapted to highly predictable conditions, while the opposite holds for reactive ones (Koolhaas, 2008).

To our knowledge, few studies have simultaneously investigated (in the same nonhuman species) the combined effects of several social and internal factors on ANS basal activity or reactivity (but see Baldock et al., 1988; Carere \& van Oers, 2004; Carnevali \& Sgoifo, 2014; Kralj-Fišer et al., 2010, for some combinations of factors). In this study, we assessed the relationship between several factors and two ANS-related physiological parameters (heart rate, 'HR', and heart rate variability, measured as the root mean square of successive interbeat intervals, 'RMSSD', which is a good estimator of vagal regulatory activity; Von Borell et al., 2007). More specifically, we tested the relationship between these physiological 
parameters and the category of behaviour performed by free-ranging goats, their dominance rank and personality traits (exploration/avoidance and sociability), as well as interactions between behaviour, rank and personality.

Goats in the wild live in large and complex social groups (Stanley \& Dunbar, 2013), with linear dominance hierarchies (Barroso, Alados, \& Boza, 2000). They express consistent individual differences in temperament, in terms of reaction to humans (timidity), which reliably predict differences in pituitary adrenal responsiveness (Lyons, 1989; Lyons, Price, \& Moberg, 1988). They also display different social identity profiles (aggressive, affiliative, passive and avoiders), which are associated with physiological differences (cortisol, glucose and nonesterified fatty acid; Pascual-Alonso et al., 2013). Furthermore, goat physiology may be affected by cognitive challenges (Langbein, Nürnberg, \& Manteuffel, 2004), social proximity while feeding and dominance rank (Aschwanden et al., 2008), confrontation with unfamiliar individuals (Patt et al., 2013), introduction to new social groups (Patt et al., 2012) and emotions (Briefer, Tettamanti, \& McElligott, 2015; Gygax, Reefmann, Wolf, \& Langbein, 2013).

We equipped the goats with a wireless monitor, released them into a large field with other goats and followed them from a distance. They were thus free to engage in any usual daytime behaviours such as eating, drinking, self-grooming, resting or interacting with other goats (agonistic or affiliative interactions). We investigated which factors, among those investigated (behaviour performed, dominance rank, personality and interactions between these factors) were mostly related to the observed physiological variation. We defined ANS basal activity as the physiological state during the behaviour characterized by the lowest HR ('baseline value'). By contrast, because the stress threshold can differ greatly between individuals and is thus difficult to determine (Koolhaas et al., 2010), we considered ANS reactivity as 'the deviation of a physiological response parameter from a comparison or control value [i.e. in our case the baseline value] that results from an individual's response to a discrete, environmental stimulus' (Matthews, 1986, p114). Therefore, ANS reactivity was defined as an increase in HR from the baseline value. According to the coping strategy concept (Koolhaas et al.,1999), we expected goats with higher avoidance score (i.e. reactive type) to have lower sympathetic reactivity and higher parasympathetic reactivity (i.e. lower HR variation compared to the baseline value and higher RMSSD). As goats live in stable dominance hierarchies (Barroso et al., 2000; Miranda-de la Lama \& Mattiello, 2010), and dominant goats are more aggressive and have easier access to food than subordinate individuals (Barroso et al., 2000; Miranda-de la Lama, Sepúlveda, Montaldo, María, \& Galindo, 2011; Stears, Kerley, \& Shrader, 2014), we also expected subordinate goats to show higher HR and lower RMSSD at rest (i.e. higher ANS basal activity), as well as higher HR variation between behaviours (i.e. higher ANS reactivity).

\section{METHODS}

\section{Subjects and Management Conditions}

The study was carried out at a goat sanctuary (Buttercups Sanctuary for Goats, http://www.buttercups.org.uk), Kent (U.K.) in 2011 and 2012. The study site contained 125 goats at the time. We tested 16 adult goats (seven females and nine castrated males), which were fully habituated to human presence because of previous and ongoing research (Baciadonna, McElligott, \& Briefer, 2013; Briefer \& McElligott, 2013). They were aged 4-13 years and of various breeds (Table 1). At night, goats were kept indoors in individual or shared pens (one to three goats per pen, average pen size $=3.5 \mathrm{~m}^{2}$ ) with straw bedding, within a larger stable complex. During the day, all goats were released together and could freely move between the stable complex and a large field ( 2 ha) containing several hay racks. Routine care of the animals was provided by sanctuary employees and volunteers. Goats had ad libitum access to hay, grass (during the day) and water, and were also fed with a commercial concentrate in quantities according to their state and age. 
Table 1. Characteristics of the goats used: breed, sex, age (years old in 2011), dominance rank and personality scores (avoidance and sociability)

\begin{tabular}{|cllcccc|}
\hline Goat & Breed & Sex & Age & Rank & Avoidance & Sociability \\
\hline 1 & Anglo Nubian & Female & 11 & 49 & 1.57 & -0.18 \\
2 & British Toggenburg & Female & 13 & 29 & -0.22 & 0.89 \\
3 & British Saanen & Female & 7 & 56 & -4.08 & -0.33 \\
4 & Pygmy goat & Female & 8 & 32 & -4.58 & -1.63 \\
5 & British Toggenburg & Female & 7 & 9 & 2.15 & -1.02 \\
6 & Golden Guernsey & Female & 11 & 58 & -1.12 & 0.36 \\
7 & British Alpine & Female & 7 & 20 & -0.59 & -0.44 \\
8 & British Toggenburg & Male & 7 & 47 & -0.12 & -0.9 \\
9 & British Toggenburg & Male & 9 & 67 & -1.27 & -1.47 \\
10 & Golden Guernsey & Male & 6 & 62 & -1.29 & -2.59 \\
11 & British Saanen & Male & 9 & 45 & -0.96 & -1.37 \\
12 & Pygmy goat & Male & 11 & 37 & -0.83 & 0.78 \\
13 & Golden Guernsey & Male & 10 & 66 & 0.34 & -2.48 \\
14 & Boer & Male & 4 & 69 & -3.35 & 1.51 \\
15 & Pygmy goat & Male & 8 & 23 & -3.44 & -1.04 \\
16 & British Toggenburg & Male & 10 & 15 & 0.66 & -0.16 \\
\hline
\end{tabular}

\section{Dominance Rank}

We observed the entire herd (125 goats) from March 2011 to April 2012 on a regular basis (for 1-3 $\mathrm{h}$ two times per week). To assess the dominance hierarchy, we scored all events of agonistic interactions, including fights, displacements, threats, aggression (head butts) and retreats (Andersen \& Bøe, 2007; Patt et al., 2012). We then calculated the ranks of all goats that interacted with at least $5 \%$ of other goats, from the outcomes of agonistic interactions resulting in a clear 'winner' and 'loser' (the winner wins the fight, displaces, threatens or is aggressive towards the loser, which, as a consequence, retreats; $N=579$ interactions involving 98 goats). Because goat herds typically have linear hierarchies (Barroso et al., 2000), we calculated dominance ranks using the Clutton-Brock index (CBI; Bang, Deshpande, Sumana, \& Gadagkar, 2010; Clutton-Brock, Albon, Gibson, \& Guinness, 1979) as follows: $\mathrm{CBI}=(B+b+1) /(L+I+$ 1 ), where $B$ is the number of goats defeated by the focal goat ('losers'), $b$ is the number of goats (excluding the focal goat) defeated by the losers, $L$ is the number of goats that defeated the focal goat ('winners') and $I$ is the number of goats that defeated the winners. We assigned the rank of 1 to the goat with the highest index, and all the other goats were ranked accordingly. In total, we ranked 72 goats. The ranks of the goats tested in this study are listed in Table 1 (see Baciadonna et al., 2013 for more details).

\section{Personality}

We assessed two personality traits: exploration/avoidance (i.e. reaction to a new situation) and sociability (i.e. reaction to the presence or absence of conspecifics; Réale et al., 2007). We measured these two traits using two tests repeated in 2 consecutive years (14-16 months interval), in order to determine individual differences that are repeatable over long periods of time and consistent between situations (Réale et al., 2007). Exploration/avoidance was measured using a novel object test and a novel surface (or area) test (Lansade, Bouissou, \& Erhard, 2008a), in a familiar environment. Sociability was measured using an isolation test and an attraction test (Lansade, Bouissou, \& Erhard, 2008b).We conducted these 
tests in March-April 2011 and repeated them in MayeJuly 2012. We measured several behavioural responses from the videos of the tests (listed in Table A1). We then carried out a principal component analysis (PCA) in order to combine all the correlated behaviours in one score, which would be representative of the response of the subjects to the tests (McGregor, 1992). From the resulting PCA (one for each personality trait), we selected the scores of the most relevant principal component (PC), verified score consistency over the two years, and averaged the PC scores calculated for 2011 and 2012 to obtain one personality score for each goat. The personality tests and methods used to calculate personality scores are detailed in the Appendix, and the resulting scores for the 16 goats tested in this study are listed in Table 1. Highly positive exploration/avoidance scores (hereafter 'avoidance scores') indicated goats that mostly avoided/did not explore the novel item, whereas highly positive sociability scores indicated highly social goats (i.e. reacted strongly to the isolation and went back quickly to the other goats during the attraction test; see Appendix).

\section{Physiology and Behaviour}

We collected physiological data (continuous electrocardiogram, 'ECG' trace) on free-ranging goats over 5 days in total in June 2011, from 1200 to 1700 hours, under similar clear weather conditions (no rain or strong wind), and after the goats had been released from the night stables around 0900 hours. This was done using a small wireless noninvasive monitor, fixed to a belt placed around the goat's chest (MLE120X BioHarness Telemetry System, Zephyr, Annapolis, MD, U.S.A.; Johnstone, Ford, Hughes, Watson, \& Garrett, 2012a, 2012b). The data were then transmitted and stored in real time to a laptop using LabChart software v.7.2 (ADInstruments, Oxford, U.K.) for later analyses (Briefer, Tettamanti, \& McElligott, 2015). We tested the goats one by one, two times each, on 2 different days (mean $\pm S D=15.00 \pm 5.79$ days of interval, $N=16$ goats). Before each session, the experimenter brought the subject to a pen that was part of the usual night stables complex. The goat was then quickly equipped with the monitor and released, once a good signal (clear ECG trace) was visible on the software. All the goats in this study had been previously habituated to wear the device, as part of another experiment on indicators of emotions (Briefer, Tettamanti, \& McElligott, 2015).

Once released, the goat was free to range among the other goats, within the stable complex or in the large field. The experimenter followed it from 10-15 m away for $30 \mathrm{~min}$, while noting directly in the physiology software the start and end of the following behavioural categories: (1) Locomotion (movements to go from A to B; excluding movements during grazing; this behaviour was not considered for the analyses because of the poor quality of the ECG trace), (2) Eat/drink (feeding on grass or hay; licking a salt lick; drinking), (3) Resting (standing up still or lying down while ruminating), (4) Scratching/self-grooming (scratching body parts using teeth; scratching against a fence/wall/fixed brush), (5) Agonistic interactions (frontal clashing/fighting; butting, chasing, displacing, biting a goat or being butted, chased, displaced or bitten by another goat; nosing on/exploring another goat before or after a frontal clash, after butting, chasing or displacing it, or while having the hair of the neck erected as a threat display), (6) Affiliative/positive interactions (resting, side by side, in body contact with another goat; grooming against another goat, i.e. scratching against the horn of the other goat). Affiliative interactions were never followed by an agonistic interaction between the two goats involved (see Andersen \& Bøe, 2007; Patt et al., 2012 for more precise definitions of the social interactions). On some occasions, the subjects approached the sanctuary employees or volunteers and were groomed by them. We scored this behaviour as an affiliative interaction (these approaches were always initiated by the goat and not the human). At the end of the 30 min following session, we removed the monitor from the goat and released it.

The data were analysed using LabChart software. When possible (i.e. good-quality signal; clearly visible heart beats on the ECG trace), we analysed physiological parameters over short selections of about $10 \mathrm{~s}$ 
(Briefer et al., 2015; Reefmann, Wechsler, \& Gygax, 2009; selection duration: mean \pm SD $=9.80 \pm 0.87$ s; $N=602$ selections for 16 goats; range $18 \mathrm{e} 58$ selections per goat) during the recorded behaviour (i.e. between the comments mentioning the start and end of the behaviour), or directly after $(<10 \mathrm{~s})$ if the signal quality was better. These short selections allowed us to identify even short-term changes in physiology linked to each behaviour, as these measures rapidly return to baseline after transient perturbations (Von Borell et al., 2007). For each selection, we ensured that the software tracked the heart beats (ECG trace) correctly (as displayed by event markers on the screen). Then, the heart rate (beats/min) was obtained automatically from the software. Individual interheart beat (RR) intervals (ms) were also extracted, in order to calculate RMSSD (ms; Briefer, Tettamanti, \& McElligott, 2015). In total, we obtained 73 selections ( $N=16$ goats) during Agonistic interactions, 259 selections ( $N=16$ goats) during Resting, 171 selections ( $N=16$ goats) during Eat/drink, 38 selections ( $N=13$ goats) during Affiliative interactions, and finally, 61 selections $(N=13$ goats) during Scratching.

\section{Statistical Analysis}

To investigate the relationship between the various types of factors (category of behaviour, dominance rank, avoidance, sociability and all possible two-way interactions) and the physiological parameters measured in free-ranging goats (heart rate and RMSSD), we carried out linear mixed-effects models (LMM; Imer function, Ime4 library) in R 3.1.0 (R Development Core Team, 2014). For each physiological variable (HR and RMSSD), we built a global model, including as explanatory factors the category of behavior (Agonistic interactions, Resting, Eat/drink, Affiliative interactions or Scratching), dominance rank (range 9-69; Table 1), avoidance and sociability scores (Table 1) and all possible two-way interactions between these factors. To control for confounding factors that could have impacted goat physiology, instead of including the original HR and RMSSD values as dependent variables, we included the residuals extracted from a model fitting the following control factors: (1) the duration of the physiological selection (range 5.32-10.8 s), because the length of the measurement period can potentially affect physiological values (Reefmann et al., 2009); and three characteristics of the goats that might also influence heart rate: (2) the breed (Table 1; Hezzell et al., 2013), (3) the sex (female or castrated male; Table 1; Olsen, Mow, Koch, \& Pedersen, 1999) and (4) the age of the goats (4-13 years old; Table 1; Hezzell et al., 2013). The resulting residuals are thus independent of all these factors. All models included the identity of the goats and the day of recording ( 5 days in total) as random crossed factors, in order to control for repeated measurements of the same subjects within and between days, and for differences between days. We checked the residuals of the models graphically for normal distribution and homoscedasticity (Bates, 2005). To satisfy these assumptions in the model carried out to extract residuals, we used log transformations for RMSSD.

We used an automated model selection procedure that generated and compared, based on the Bayesian information criterion (BIC; Schwarz, 1978), a set of models with combinations (subsets) of the terms present in the global model, in order to identify which model(s) best explained HR and RMSSD (dredge function, MuMIn library in R). We used BIC instead of the now more commonly used Akaike's information criterion (AIC; Aho, Derryberry, \& Peterson, 2014), because BIC penalizes the number of explanatory factors included in the model more strongly than AIC (thus selecting a smaller number of models and preventing overfitting more efficiently), and is more appropriate for studying mechanisms, i.e. the causal understanding of the relation between explanatory factors and dependent variables (Aho et al., 2014; Myung, 2000; see Gygax et al., 2013; Patt et al., 2012 for example of case study on goats). The best model among a set is the model with the lowest BIC. As BIC penalizes the number of explanatory factors, lower BICs imply better fit, fewer explanatory factors, or both. The evidence for the best model is as follows: when the difference between the BIC values of the best model and the second best models $(\triangle \mathrm{BIC})$ is less than 2 units, the evidence is weak. When $\triangle \mathrm{BIC}$ ranges from 2 to 6 , there is positive 
evidence for the best model. $\triangle \mathrm{BIC}$ ranging between 6 and 10 suggests strong evidence for the best model, while $\triangle \mathrm{BIC}>10$ suggests decisive evidence (Kass \& Raftery, 1995; Raftery, 1996). BIC weights $(\omega i)$ are normalized across the selected models to sum to one, and are interpreted as probabilities. They indicate the probability that a particular model has to be the best model among those included in the set of candidate models. To compare models with BIC, all models were fitted with maximum likelihood estimation. We also assessed the significance of each factor or interaction of factors in the lowest-BIC model in which it appeared, by comparing the model with and without the factor included using likelihoodratio tests.

To test the effect of personality on ANS reactivity, we additionally calculated the effect of sociability scores on the variation in HR between the behaviour triggering the highest HR (Eat/drink) and the behaviour triggering the lowest HR (Affiliative interactions; Fig. 1a), using a linear model (Im function, stats library in R). The model included the variation in HR as a dependent variable. This variable was calculated as the mean HR residuals per goat (extracted from the model controlled for selection duration, breed, sex, age, goat identity and day of data collection) measured during Eat/drink minus those measured during Affiliative interactions. The sociability score was included as a fixed effect. The significance level was set at $\alpha=0.05$. All the means are given with SD.

\section{Ethical Note}

Animal care and all experimental procedures were in accordance with the ASAB/ABS Guidelines for the Use of Animals in Research. The research plan was reviewed by the U.K. Government Home Office inspector for Queen Mary, University of London. All measurements were noninvasive, and the situations used to assess the personality of the goats (e.g. novel object and isolation) lasted no more than 5 min each. The stress levels of the goats (indicated by their behaviour and/or physiology) were monitored throughout the tests (ECG trace was transmitted and displayed, in real time on the laptop) to ensure the wellbeing of the subjects. If the goats had become stressed, the test would have been halted and the subject would not be tested anymore. As detailed in the Appendix, two goats tested with the personality tests showed signs of stress during the first habituation to the attraction test and were not willing to follow the experimenter away from the other goats. They were thus not tested further for this personality trait.

\section{RESULTS}

\section{Heart Rate $(H R)$}

Our model selection procedure based on BIC revealed that the model with the highest probability for HR included the behavioural category, sociability and the interaction effect between these two factors (model probability $=77.7 \%$; model 1 , Table 2$)$. As this model contained several factors $(d f=13)$ and had a high probability, it is thus strongly supported by the data. The next model (model 2, Table 2) included, in addition, the dominance rank, and had a probability of $10.0 \%$. The DBIC between this second model and the third (probability $=5.1 \%$ ) and fourth (probability $=4.6 \%$ ) models was less than 2 units, indicating these three models (models 2-4, Table 2) were similarly supported. The third model included the same factors as the best model, with, in addition, avoidance, while the fourth model included only the behavioural category. The model probability then dropped to $<1.1 \%$ for the remaining models (Table 2 ). Therefore, the variance in HR values was best explained by the category of behaviour performed and sociability, as well as how these factors interacted.

HR differed between behavioural categories (Table 2). It was highest during the behavioural category Eat/drink and lowest during Affiliative interactions (Fig. 1a). There was no effect of sociability on HR, but there was a significant interaction effect between behavioural category and sociability (model 1, Table 2). 
Post hoc analyses showed that HR increased with sociability scores during behaviours triggering lower HR (likelihood-ratio tests: Affiliative interactions: $X^{2}{ }_{1}=5.98, P=0.014$, Fig. 2a; Resting: $X^{2}{ }_{1}=5.61, P=$ 0.018, Fig. 2b; Scratching: $X^{2}{ }_{1}=4.01, P=0.045$, Fig. $2 \mathrm{c}$ ), while it tended to decrease during the behaviour with the highest $\mathrm{HR}$ (Eat/drink: $X^{2}{ }_{1}=3.42, P=0.065$, Fig. $2 \mathrm{e}$ ). However, the apparent decrease with sociability during Agonistic interactions (slope $=-0.30$ ) was not significant $\left(X^{2}=0.14, P=\right.$ 0.71, Fig. 2d). Overall, Fig. 2a-e suggested more variation in HR between behaviours in less social goats. By contrast, more social goats seemed to have a more stable HR (model residuals around 0 for all behaviours). Additional analyses showed that, indeed, HR variation (measured as the difference in HR between the behaviour triggering the highest HR, i.e. Eat/drink, and the behaviour triggering the lowest $\mathrm{HR}$, i.e. Affiliative interactions) decreased with sociability (linear model: $t_{11}=-3.70, N=13, P=0.003$; Fig. 3). Finally, the effects of dominance rank (model 2) and avoidance (model 3) were not significant (Table 2).

Table 2. Results of the model selection for comparing the effect of the tested factors on goat physiology

\begin{tabular}{|c|c|c|c|c|c|c|c|c|c|c|}
\hline Parameter & Model & Behaviour & Rank & Avoidance & Sociability & $\begin{array}{l}\text { Behaviour: } \\
\text { Sociability }\end{array}$ & df & BIC & $\Delta \mathrm{BIC}$ & wi (\%) \\
\hline \multirow[t]{5}{*}{ HR } & 1 & $\begin{array}{l}+ \\
X^{2}{ }_{4}=220.82 \\
P<0.0001\end{array}$ & & & $\begin{array}{l}+ \\
X^{2}{ }_{1}=0.54 \\
P=0.46\end{array}$ & $\begin{array}{l}+ \\
X^{2}{ }_{4}=37.13 \\
P<0.00001\end{array}$ & 13 & 4292.6 & 0.00 & 77.7 \\
\hline & 2 & + & $\begin{array}{l}+ \\
X^{2}{ }_{1}=2.29 \\
P=0.13\end{array}$ & & & + & 14 & 4296.7 & 4.11 & 10.0 \\
\hline & 3 & + & & $\begin{array}{l}+ \\
X^{2}{ }_{1}=0.95 \\
P=0.33\end{array}$ & + & + & 14 & 4298.0 & 5.45 & 5.1 \\
\hline & 4 & + & & & & & 8 & 4298.2 & 5.67 & 4.6 \\
\hline & 5 & + & + & & & & 9 & 4301.0 & 8.48 & 1.1 \\
\hline \multirow[t]{5}{*}{ RMSSD } & 1 & & & & & & 4 & 624.4 & 0.00 & 85.1 \\
\hline & 2 & $\begin{array}{l}+ \\
X^{2}{ }_{4}=220.28 \\
P<0.0001\end{array}$ & & & & & 8 & 630.8 & 6.36 & 3.5 \\
\hline & 3 & & & & $\begin{array}{l}+ \\
X^{2}{ }_{1}=0.00 \\
P=0.97\end{array}$ & & 5 & 630.8 & 6.40 & 3.5 \\
\hline & 4 & & & $\begin{array}{l}+ \\
X^{2}{ }_{1}=0.00 \\
P=0.96\end{array}$ & & & 5 & 630.8 & 6.40 & 3.5 \\
\hline & 5 & & $\begin{array}{l}+ \\
X^{2}{ }_{1}=0.00 \\
P=0.99\end{array}$ & & & & 5 & 630.8 & 6.40 & 3.5 \\
\hline
\end{tabular}

Model selection (linear mixed-effects models) based on the Bayesian information criterion (BIC), to investigate which factors (category of behaviour, dominance rank, avoidance and sociability) and their interactions best explained the variance in the heart rate (HR) and heart rate variability (measured as the root mean square of successive interbeat intervals, 'RMSSD') of free-ranging goats. Only the first five models, ranked from the best model (1) to the less likely (5), are shown (other possible models had a $w i \leq 0.5 \%$ ). For each factor, ' + ' indicates that it was included in the selected model. The statistical significance (likelihood-ratio tests: $X^{2}$ df and $P$; significant results in bold) was calculated for each factor in the lowest-BIC model in which it appeared. Interactions that were not included in these five best models are not shown (Behaviour:Rank, Behaviour:Avoidance, Rank:Avoidance, Rank:Sociability and Avoidance:Sociability). The sample size was 602 data points and 16 goats. The fit of the models is assessed by BIC; the lowest value for a given response variable (i.e. set of models) indicates the best fit (in bold). df indicates the degrees of freedom used by the fixed effects in the model. $\triangle \mathrm{BIC}$ gives the difference in BIC between each model and the best model within the set. The BIC's weight $(\omega i)$ assesses the relative support that a given model has from the data, compared to other candidate models in the set. All models were carried out with the residuals of HR or RMSSD as response variables, controlled for the selection duration, breed, sex and age. All models included the identity of the goats and the day of data collection as a random factor. 
Figure 2. Relationship between physiology and sociability for each behavioural category. Heart rate (residuals of the models controlled for duration, breed, sex, age, goat's identity and day of data collection; mean per goat; $N=16$ goats) as a function of sociability score from the category triggering the lowest heart rate to that triggering the highest heart rate (Fig. 1a): (a) Affiliative interactions, (b) Resting, (c) Scratching, (d) Agonistic interactions, (e) Eat/drink. The lines indicate the best fits for each behavioural category. The slopes of the best fits and significance of the relationships (likelihood-ratio tests: ${ }^{*}<0.05$ ) are also indicated.
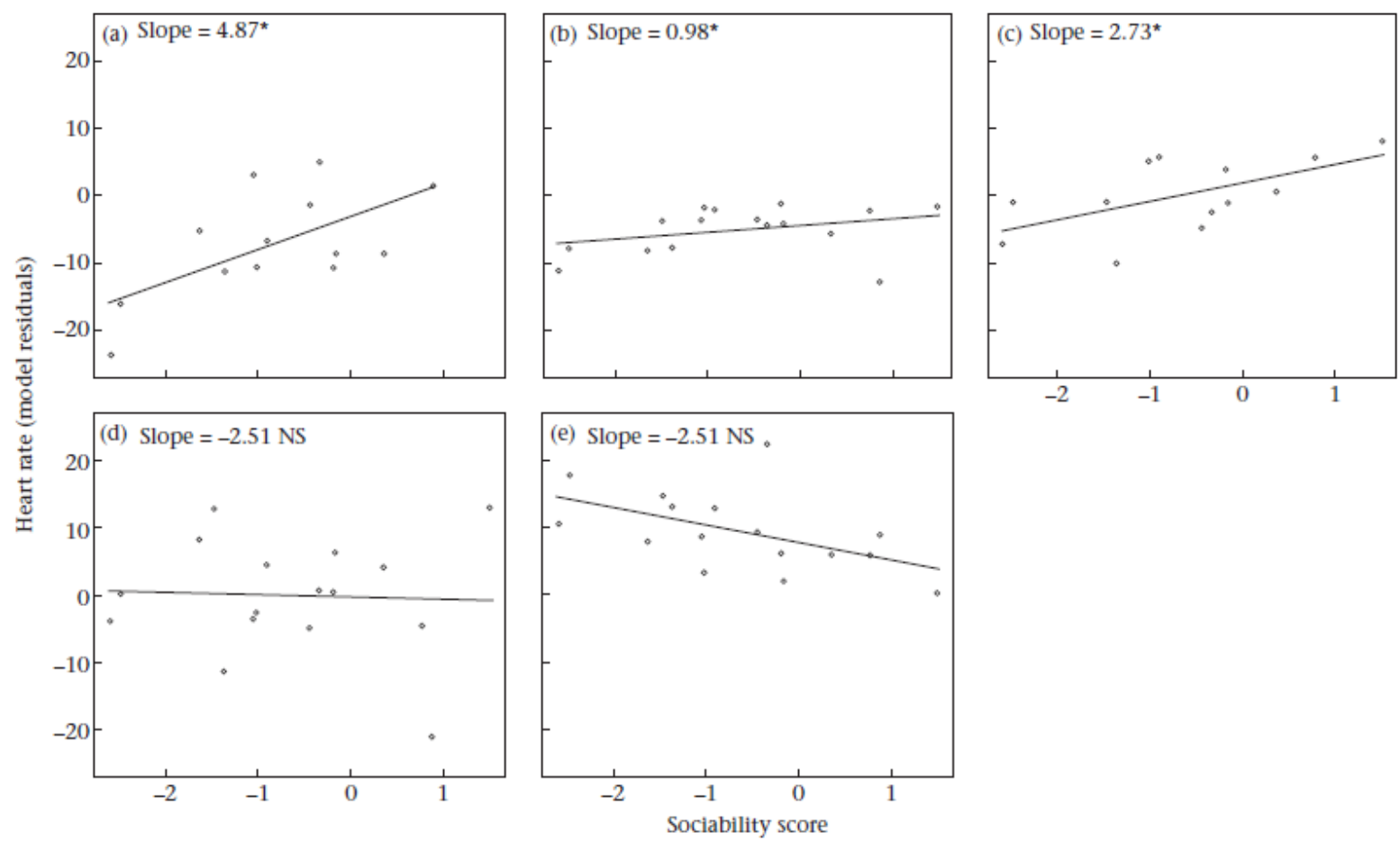

Figure 3. Relationship between the variation in heart rate and sociability. Differences between the heart rate of goats (residuals of the models controlled for selection duration, breed, sex, age, goat's identity and day of data collection; mean per goat; $N=13$ goats) measured during Eat/drink (highest heart rate behaviour) and Affiliative interactions (lowest heart rate behaviour; Fig. 1a), as a function of sociability scores. The best fit is indicated.

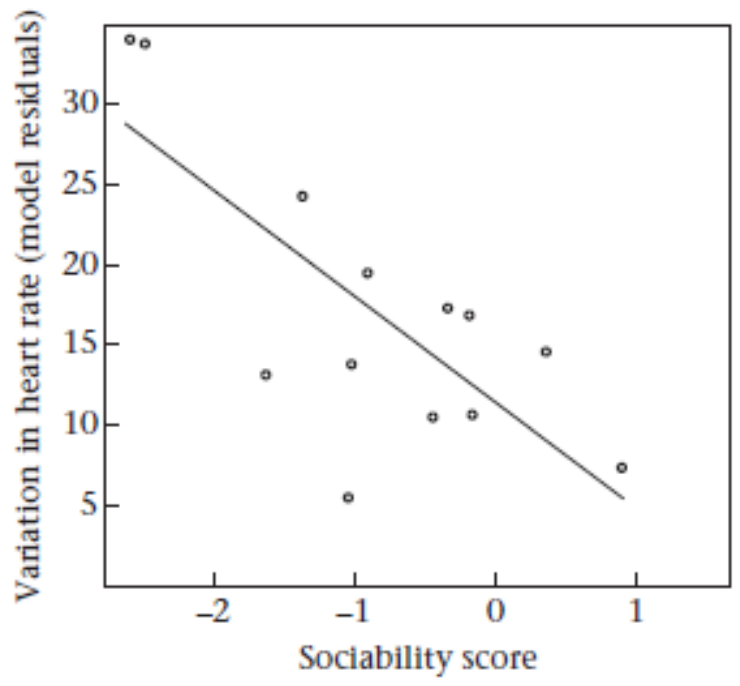


Our model selection procedure revealed that the model with the highest probability for RMSSD was the null model, including the intercept and random factors only (model probability $=85.1 \%$; Table 2 ). This suggests that the remaining variance in RMSSD after removing the effects of the control factors (selection duration, breed, sex and age; i.e. model residuals included as the dependent variable) was not strongly affected by any of the considered fixed factors (behavioural category, dominance rank, sociability and avoidance). The next four models (models 2-5, Table 2) had similar BIC and probabilities (3.5\%). The model probability then dropped to $\leq 0.2 \%$ for the following models (not shown in Table 2), which were more complex. This suggests that models 2-5 received a low BIC because they included a low number of factors, more than because they had a good fit. Therefore, there was only weak evidence for an effect of the factors considered on RMSSD.

RMSSD differed between behavioural categories (Table 2). It was highest during Affiliative interactions and lowest during Eat/drink (Fig. 1b). The effects of sociability (model 3), avoidance (model 4) and dominance rank (model 5) were not significant (Table 2).

\section{DISCUSSION}

We measured heart rate (HR) and heart rate variability (RMSSD) in free-ranging goats, to investigate which social and internal factors are related to the autonomic nervous system (ANS) basal activity and reactivity of these animals. We tested the relationships between the physiological parameters and the category of behavior performed by free-ranging goats (Agonistic interactions, Resting, Eat/drink, Affiliative interactions and Scratching), dominance rank, personality (avoidance and sociability), as well as the interactions between these factors. We found that the variation in HR was best explained by the category of behaviour performed, sociability and the interaction between these two factors. HR was highest during the behavioural category Eat/drink and lowest during Affiliative interactions. This parameter increased with sociability during behaviours characterized by low $\mathrm{HR}$, while the opposite tended to occur during behaviours characterized by high HR. This pattern was explained by higher HR variation between behaviours in less social goats. By contrast, more social goats had a more stable HR, suggesting lower ANS reactivity (i.e. lower HR response). RMSSD was also affected by the category of the behaviour performed by the goats and was lowest during the behavioural category Eat/drink and highest during Affiliative interactions. There was no effect of dominance rank or avoidance on HR or RMSSD. Therefore, our results on free-ranging goats highlight the relationships between physiology and personality, which may depend on the specific behaviour performed (Koolhaas et al., 2010; Réale et al., 2007).

\section{Behavioural Category}

The category of behaviour performed (Agonistic interactions, Resting, Eat/drink, Affiliative interactions or Scratching) was related to both HR and RMSSD. This relationship could be due to the underlying emotional arousal (i.e. activation) triggered by the situation in which the behaviour occurred (Briefer, Tettamanti, \& McElligott, 2015; Wascher, Arnold, \& Kotrschall, 2008). Indeed, an increase in emotional arousal during both positive and negative situations usually induces an increase in HR and other physiological parameters (e.g. respiration rate and skin temperature) as well as a decrease in RMSSD (Briefer et al., 2015; Zebunke, Langbein, Manteuffel, \& Puppe, 2011). Alternatively, the behavioural category could be related to physiological parameters through the physical activity required to perform the behaviour (metabolic requirements of activated tissues; Koolhaas et al., 2011; Major, 1998; Wascher et al., 2008), and even subtle activity such as body movements while resting or movement levels can affect heart rate (Major, 1998; Willener et al., 2014). Our results might fit the emotional arousal hypothesis better than the physical activity hypothesis. Indeed, the HR of goats (Affiliative interactions < Resting < 
Scratching < Agonistic interactions < Eat/Drink; Fig. 1a) does not seem to reflect precisely the expectation of physical activity associated with each behaviour (i.e. likely: Resting < Affiliative interactions < Scratching < Eat/drink < Agonistic interactions), but could potentially reflect the expectation of emotional arousal. For example, HR was highest during Eat/drink, which is likely to be an emotionally positive-high arousal situation, but that clearly requires lower physical activity than agonistic interactions (e.g. fighting, head butting, chasing, displacing). Wascher et al. (2008) proposed a similar emotional involvement effect on HR in greylag geese, after finding higher HR in behaviours performed in social than nonsocial contexts, despite involving similar activity levels.

Interestingly, HR was lowest, and RMSSD highest, during affiliative interactions. RMSSD mainly depends on vagal influences and thus indicates when the parasympathetic system is activated (Von Borell et al., 2007). This suggests an activation of the vagal branch of the ANS in goats during affiliative interactions. Similar reductions in HR have been observed when the subject is being groomed by conspecifics in primates (Boccia, Reite, \& Laudenslager, 1989; Filippo, Preston, \& de Waal, 1999) and in cattle, Bos Taurus (Laister et al., 2011). Furthermore, our affiliative interactions also included voluntary grooming by humans, which has been shown to decrease (or to tend to decrease) HR or cortisol in other species (e.g. horses, Equus caballus, Feh \& de Mazi_eres, 1993; sheep, Ovis aries, Reefmann et al., 2009).

\section{Personality}

We did not find evidence for the relationship between avoidance scores and ANS reactivity predicted by the coping strategy concept (i.e. lower sympathetic and higher parasympathetic reactivity in more neophobic goats, i.e. reactive type; Koolhaas et al., 1999). There was also no effect of sociability alone on $\mathrm{HR}$ and RMSSD. However, there was an interaction effect between sociability and the category of behaviour performed on HR. Overall, less social goats showed a higher HR response than social goats (in which HR was more stable), indicating an effect of sociability on ANS reactivity. Similarly, Wascher et al. (2008) found that less social greylag geese had higher HR than more social ones during agonistic interactions, which were characterized by high HR. The coping strategy concept (e.g. Koolhaas et al., 1999) and the pace-of-life syndrome concept (e.g. R_eale et al., 2010) suggest that proactive (coping strategy) or fast individuals (pace of life) have higher ANS reactivity than reactive or slow individuals. The link between proactive/reactive and sociability is not clear, but R_eale et al. (2010) proposed that fast individuals are expected to be less social. In this case, our results are consistent with these concepts in suggesting that less social goats (i.e. likely proactive goats) show higher sympathetic reactivity than more social ones. These differences could have consequences in the wild, with more reactive goats being better able to cope in changing environments, unlike proactive goats, which form routines (i.e. rigid type of behaviour) and are less flexible (Koolhaas et al., 1999).

\section{Dominance Rank}

We did not find any effects of dominance rank on physiology. Subordinate individuals can show lower or higher stress levels than dominant ones, depending on the social organization of the species (Abbott et al., 2003; Sapolsky, 2005). In stable hierarchies, such as those found in goats (Barroso et al., 2000; Miranda-de la Lama \& Mattiello, 2010), subordinates are expected to suffer more from stress than dominant individuals, as a result of psychological harassment from dominant individuals, lack of social control and difficult access to food (Sapolsky, 2005). Accordingly, dominant goats are more aggressive and have easier access to food than subordinate individuals (Barroso et al., 2000; Miranda-de la Lama et al., 2011; Stears et al., 2014). Therefore, we could have expected higher heart rates and lower heart rate variability in subordinate goats than dominant ones. Previous studies found evidence for both higher stress levels (higher heart rate and lower heart rate variability, Aschwanden et al., 2008) and lower stress levels (lower cortisol level; Miranda-de la Lama et al., 2013) in subordinate goats than dominant ones. 
Additionally, Pascual-Alonso et al. (2013) found the highest cortisol levels in middle-ranking goats, suggesting that the relationship between rank and physiological measures in goats is not linear. Further analyses could test whether the effect of rank on goat physiology depends on (and changes according to) the particular social context in which the goat finds itself (Aschwanden et al., 2008; e.g. by comparing the relationship between physiology and rank when the goat is feeding close to a more dominant versus subordinate individual).

\section{Conclusion}

Our study shows that the category of behaviour performed and the personality of the goats are related to ANS reactivity. These results on a free-ranging mammal strengthen the evidence suggesting that individual differences in behaviour are related to underlying physiology (Koolhaas et al., 2010).

\section{Acknowledgments}

We are grateful to Luigi Baciadonna, Samaah Haque and Federico Tettamanti for their help during data collection, and to Antonia Patt, Claudia Wascher and two anonymous referees for helpful comments on the manuscript. We are very grateful to Switzerland for funding this study in the U.K. This was achieved through a Swiss Federal Veterinary Office grant (Project No. 2.11.03) to A.G.M. and E.F.B., and a Swiss National Science Foundation fellowship to E.F.B (Project No. PA00P3_131485).We thank Bob Hitch, Natalie Comfort and all the volunteers of Buttercups Sanctuary for Goats (http://www.buttercups.org.uk) for their ongoing excellent support and free access to the animals.

\section{References}

Abbott, D., Keverne, E., Bercovitch, F., Shively, C., Mendoza, S., Saltzman, W., et al. (2003). Are subordinates always stressed? A comparative analysis of rank differences in cortisol levels among primates. Hormones and Behavior, 43, 67-82.

Aho, K., Derryberry, D., \& Peterson, T. (2014). Model selection for ecologists: the worldviews of AIC and BIC. Ecology, 95, 631-636.

Andersen, I. L., \& Bøe, K. E. (2007). Resting pattern and social interactions in goats--The impact of size and organisation of lying space. Applied Animal Behaviour Science, 108, 89-103.

Aschwanden, J., Gygax, L.,Wechsler, B., \& Keil, N. M. (2008). Cardiac activity in dairy goats whilst feeding side-by-side at two different distances and during social separation. Physiology \& Behaviour, 95, 641-648.

Baciadonna, L., McElligott, A. G., \& Briefer, E. F. (2013). Goats favour personal over social information in an experimental foraging task. PeerJ, 1, e172.

Baldock, N. M., Sibly, R. M., \& Penning, P. D. (1988). Behaviour and seasonal variation in heart rate in domestic sheep, Ovis aries. Animal Behaviour, 36, 35-43.

Bang, A., Deshpande, S., Sumana, A., \& Gadagkar, R. (2010). Choosing an appropriate index to construct dominance hierarchies in animal societies: a comparison of three indices. Animal Behaviour, 79, 631-636.

Barroso, F. G., Alados, C. L., \& Boza, J. (2000). Social hierarchy in the domestic goat: effect on food habits and production. Applied Animal Behaviour Science, 69, 35-53.

Bates, D. (2005). Fitting linear mixed models in R. R News, 5, 27-30.

Boccia, M. L., Reite, M., \& Laudenslager, M. (1989). On the physiology of grooming in a pigtail macaque. Physiology \& Behavior, 45, 667-670. 
Briefer, E. F., Maigrot, A.-L., Mandel, R., Briefer Freymond, S., Bachmann, I., \& Hillmann, E. (2015b). Segregation of information about emotional arousal and valence in horse whinnies. Scientific Reports, 4, 9989.

Briefer, E. F., \& McElligott, A. G. (2013). Rescued goats at a sanctuary display positive mood after former neglect. Applied Animal Behaviour Science, 146, 45-55.

Briefer, E. F., Tettamanti, F., \& McElligott, A. G. (2015a). Emotions in goats: mapping physiological, behavioural and vocal profiles. Animal Behaviour, 99, 131-143.

Carere, C., \& van Oers, K. (2004). Shy and bold great tits (Parus major): body temperature and breath rate in response to handling stress. Physiology \& Behavior, 82, 905-912.

Carnevali, L., \& Sgoifo, A. (2014). Vagal modulation of resting heart rate in rats: the role of stress, psychosocial factors, and physical exercise. Frontiers in Physiology, 5, 118.

Clutton-Brock, T. H., Albon, S. D., Gibson, R. M., \& Guinness, F. E. (1979). The logical stag: adaptive aspects of fighting in red deer (Cervus elaphus L.). Animal Behaviour, 27, 211-225.

Creel, S. (2001). Social dominance and stress hormones. Trends in Ecology and Evolution, 16, 491-497.

Creel, S., Dantzer, B., Goymann,W., \& Rubenstein, D. R. (2013). The ecology of stress: effects of the social environment. Functional Ecology, 27, 66-80.

Feh, C., \& de Mazières, J. (1993). Grooming at a preferred site reduces heart rate in horses. Animal Behaviour, 46, 1191-1194.

Filippo, A., Preston, S. D., \& de Waal, F. B. M. (1999). Heart rate responses to social interactions in freemoving rhesus macaques (Macaca mulatta). Journal of Comparative Physiology, 113, 59-65.

Gosling, S. D. (2001). From mice to men: what can we learn about personality from animal research? Psychological Bulletin, 127, 45-86.

Gygax, L., Reefmann, N., Wolf, M., \& Langbein, J. (2013). Prefrontal cortex activity, sympatho-vagal reaction and behaviour distinguish between situations of feed reward and frustration in dwarf goats. Behavioural Brain Research, 239, 104-114.

Hänninen, L., \& Pastell, M. (2009). CowLog: open source software for coding behaviors from digital video. Behavior Research Methods, 41, 472-476.

Hezzell, M. J., Humm, K., Dennis, S. G., Agee, L., \& Boswood, A. (2013). Relationships between heart rate and age, bodyweight and breed in 10,849 dogs. Journal of Small Animal Practice, 54, 318324.

Johnstone, J. A., Ford, P. A., Hughes, G., Watson, T., \& Garrett, A. T. (2012a). Bioharness(TM) multivariable monitoring device: part. I: validity. Journal of Sports Science \& Medicine, 11, 400408.

Johnstone, J. A., Ford, P. A., Hughes, G., Watson, T., \& Garrett, A. T. (2012b). Bioharness(TM) multivariable monitoring device: part. II: reliability. Journal of Sports Science \& Medicine, 11, 409417.

Kass, R. E., \& Raftery, A. E. (1995). Bayes factors. Journal of the American Statistical Association, 90, 773-795.

Koolhaas, J. M. (2008). Coping style and immunity in animals: making sense of individual variation. Personality and Disease, 22, 662-667.

Koolhaas, J. M., Bartolomucci, A., Buwalda, B., de Boer, S. F., Flügge, G., Korte, S. M., et al. (2011). Stress revisited: a critical evaluation of the stress concept. Neuroscience \& Biobehavioral Reviews, 35, 1291-1301.

Koolhaas, J. M., de Boer, S. F., Coppens, C. M., \& Buwalda, B. (2010). Neuroendocrinology of coping styles: towards understanding the biology of individual variation. Frontiers in Neuroendocrinology, 31, 307-321.

Koolhaas, J., Korte, S., De Boer, S., Van Der Vegt, B., Van Reenen, C., Hopster, H., et al. (1999). Coping styles in animals: current status in behavior and stress-physiology. Neuroscience \& Biobehavioral Reviews, 23, 925-935. 
Kralj-Fišer, S.,Weiß, B., \& Kotrschal, K. (2010). Behavioural and physiological correlates of personality in greylag geese (Anser anser). Journal of Ethology, 28, 363-370.

Laister, S., Stockinger, B., Regner, A.-M., Zenger, K., Knierim, U., \& Winckler, C. (2011). Social licking in dairy cattle--Effects on heart rate in performers and receivers. Applied Animal Behaviour Science, 130, 81-90.

Langbein, J., Nürnberg, G., \& Manteuffel, G. (2004). Visual discrimination learning in dwarf goats and associated changes in heart rate and heart rate variability. Physiology \& Behavior, 82, 601-609.

Lansade, L., Bouissou, M.-F., \& Erhard, H. W. (2008a). Fearfulness in horses: a temperament trait stable across time and situations. Applied Animal Behaviour Science, 115, 182-200.

Lansade, L., Bouissou, M.-F., \& Erhard, H. W. (2008b). Reactivity to isolation and association with conspecifics: a temperament trait stable across time and situations. Applied Animal Behaviour Science, 109, 355-373.

Lillywhite, H. B., Zippel, K. C., \& Farrell, A. P. (1999). Resting and maximal heart rates in ectothermic vertebrates. Comparative Biochemistry and Physiology A, 124, 369-382.

Lyons, D. M. (1989). Individual differences in temperament of dairy goats and the inhibition of milk ejection. Applied Animal Behaviour Science, 22, 269-282.

Lyons, D. M., Price, E. O., \& Moberg, G. P. (1988). Social modulation of pituitary-adrenal responsiveness and individual differences in behavior of young domestic goats. Physiology \& Behavior, 43, 451458.

MacArthur, R. A., Johnston, R. H., \& Geist, V. (1979). Factors influencing heart rate in free-ranging bighorn sheep: a physiological approach to the study of wildlife harassment. Canadian Journal of Zoology, 57, 2010-2021.

Major, P. (1998). Subtle physical activity poses a challenge to the study of heart rate. Physiology \& Behavior, 63, 381-384.

Matthews, K. (1986). Summary, conclusions and implications. In K. A. Matthews, S. M. Weiss, T. Detre, T. M. Dembrowski, B. Falkner, S. B. Manuck, et al. (Eds.), Handbook of stress, reactivity and cardiovascular disease (pp. 461-473). New York, NY: Wiley-Interscience.

McGregor, P. (1992). Playback and studies of animal communication. New York, NY: Plenum Press.

Miranda-de la Lama, G. C., \& Mattiello, S. (2010). The importance of social behavior for goat welfare in livestock farming. Small Ruminant Research, 90, 1-10.

Miranda-de la Lama, G. C., Pinal, R., Fuchs, K., Montaldo, H. H., Ducoing, A., \& Galindo, F. (2013). Environmental enrichment and social rank affects the fear and stress response to regular handling of dairy goats. Journal of Veterinary Behavior, 8, 342-348.

Miranda-de la Lama, G. C., Sepúlveda, W. S., Montaldo, H. H., María, G. A., \& Galindo, F. (2011). Social strategies associated with identity profiles in dairy goats. Applied Animal Behaviour Science, 134, 48-55.

Myung, I. J. (2000). The importance of complexity in model selection. Journal of Mathematical Psychology, 44, 190-204.

Noujaim, S. F., Lucca, E., Munoz, V., Persaud, D., Berenfeld, O., Meijler, F. L., et al. (2004). From mouse to whale: a universal scaling relation for the PR interval of the electrocardiogram of mammals. Circulation, 110, 2802-2808.

Olsen, L. H., Mow, T., Koch, J., \& Pedersen, H. D. (1999). Heart rate variability in young, clinically healthy Dachshunds: influence of sex, mitral valve prolapse status, sampling period and time of day. Journal of Veterinary Cardiology, 1, 7-16.

Pascual-Alonso, M., María, G. A., Sepúlveda, W. S., Villarroel, M., Aguayo-Ulloa, L., Galindo, F., et al. (2013). Identity profiles based on social strategies, morphology, physiology, and cognitive abilities in goats. Journal of Veterinary Behavior, 8, 458-465. 
Patt, A., Gygax, L., Wechsler, B., Hillmann, E., Palme, R., \& Keil, N. M. (2012). The introduction of individual goats into small established groups has serious negative effects on the introduced goat but not on resident goats. Applied Animal Behaviour Science, 138, 47-59.

Patt, A., Gygax, L., Wechsler, B., Hillmann, E., Palme, R., \& Keil, N. M. (2013). Behavioural and physiological reactions of goats confronted with an unfamiliar group either when alone or with two peers. Applied Animal Behaviour Science, 146, 56-65.

R Development Core Team. (2014). R foundation for statistical computing. Vienna, Austria. Retrieved from: http://www.R-project.org.

Raftery, A. E. (1996). Approximate Bayes factors and accounting for model uncertainty in generalised linear models. Biometrika, 83, 251-266.

Réale, D., Garant, D., Humphries, M. M., Bergeron, P., Careau, V., \& Montiglio, P.-O. (2010). Personality and the emergence of the pace-of-life syndrome concept at the population level. Philosophical Transactions of the Royal Society B, 365, 4051-4063.

Réale, D., Reader, S. M., Sol, D., McDougall, P. T., \& Dingemanse, N. J. (2007). Integrating animal temperament within ecology and evolution. Biological Reviews, 82, 291-318.

Reefmann, N., Wechsler, B., \& Gygax, L. (2009). Behavioural and physiological assessment of positive and negative emotion in sheep. Animal Behaviour, 78, 651-659.

Sapolsky, R. M. (2005). The influence of social hierarchy on primate health. Science, 308, 648-652.

Schwarz, G. (1978). Estimating the dimension of a model. Annals of Statistics, 6, 461-464.

Seyle, H. (1976). The stress of life. New York, NY: McGraw-Hill.

Stahl, W. R. (1967). Scaling of respiratory variables in mammals. Journal of Applied Physiology, 22, 453460.

Stanley, C. R., \& Dunbar, R. I. M. (2013). Consistent social structure and optimal clique size revealed by social network analysis of feral goats, Capra hircus. Animal Behaviour, 85, 771-779.

Stears, K., Kerley, G. I. H., \& Shrader, A. M. (2014). Group-living herbivores weigh up food availability and dominance status when making patch-joining decisions. PLoS One, 9, e109011.

Steimer, T., \& Driscoll, P. (2003). Divergent stress responses and coping styles in psychogenetically selected roman high-(RHA) and low-(RLA) avoidance rats: behavioural, neuroendocrine and developmental aspects. Stress, 6, 87-100.

Turbill, C., Ruf, T., Rothmann, A., \& Arnold,W. (2013). Social dominance is associated with individual differences in heart rate and energetic response to food restriction in female red deer. Physiological and Biochemical Zoology, 86, 528-537.

Von Borell, E., Langbein, J., Després, G., Hansen, S., Leterrier, C., Marchant-Forde, J., et al. (2007). Heart rate variability as a measure of autonomic regulation of cardiac activity for assessing stress and welfare in farm animals-A review. Physiology \& Behavior, 92, 293-316.

Wascher, C. A. F., Arnold,W., \& Kotrschall, K. (2008). Heart rate modulation by social contexts in greylag geese (Anser anser). Journal of Comparative Psychology, 122, 100-107.

Willener, A. S., Hasley, L. G., Strike, S., Enstipp, M. R., Georges, J., \& Handrich, Y. (2014). Reassessment of the cardio-respiratory stress response, using the king penguin as a model. Stress, 29, 1-6.

Zebunke, M., Langbein, J., Manteuffel, G., \& Puppe, B. (2011). Autonomic reactions indicating positive affect during acoustic reward learning in domestic pigs. Animal Behaviour, 81, 481-489. 


\section{Appendix. Personality Tests and Personality Score Calculation}

\section{Subjects}

We repeated the personality tests carried out to assess the exploration/avoidance and sociability of the goats during 2 consecutive years (interval of 14-16 months), in 2011 and 2012. They were performed on 28 goats (12 females and 13 castrated males) at Buttercups Sanctuary for Goats (Kent, U.K.), including the 16 goats in which we measured the physiology while they were free-ranging (Table 1).

\section{Experimental procedure}

We assessed exploration/avoidance (i.e. reaction to a new situation; Réale et al., 2007) using a novel object test and a novel surface test (Lansade et al., 2008a) in a familiar environment. Sociability (i.e. reaction to the presence or absence of conspecifics; Réale et al., 2007) was tested using an isolation test and an attraction test (Lansade et al., 2008b). The novel object, novel surface and isolation tests took place inside a familiar stable complex, in a $2 \times 2.26 \mathrm{~m}^{2}$ pen (A). This pen was situated next to a $2.26 \times$ $2.56 \mathrm{~m}^{2}$ pen (B), in which an audience goat could be placed, in order to avoid stress linked to isolation during the novel object and novel surface tests. The audience goat (one for each subject) was an individual that was familiar to the subject (when available, its pen mate, i.e. goat sharing its pen at night), and that we had never seen involved in agonistic interactions with the subject during our observations (see section Dominance rank). The same goats were tested together, either as subject or audience, throughout the experiment. To habituate the goats to the test pens A and B, we placed the pair of goats in the two adjacent pens, with the door between the two pens open and hay in the feeders, for 3 days during $10 \mathrm{~min} /$ day the first year (2011) and for 2 days during $5 \mathrm{~min} /$ day the second year (2012). The attraction test was carried out outdoors in a familiar field, which was part of the usual daytime range. To habituate the goats to the procedure used for this test and avoid stress linked to novelty, we brought the subjects once per day to the test field for 2 days during the first year (2011) and 1 day during the second year (2012). We led them on a rope to the field, one by one, left them there for 2 min while other individuals were grazing nearby, and then brought them back to the stable complex. The habituation to the pens and to the attraction test were carried out on different days. The number of calls and faeces produced were scored and resulted in only 0.46 calls/goat and 0.06 faeces/goat on the last day of habituation to the pens, and 0.20 calls/goat and 0.08 faeces/goat on the last day of habituation to the attraction test (average for the 2 years).

(1) Exploration/avoidance. For the novel object test, we tested the goats with two objects, presented simultaneously each year. The first year, goats were exposed to a blue umbrella and a beige lamp shade. The second year, they were exposed to a yellow salad spinner and a green pasta strainer. Both objects were placed in the left corner of pen A, opposite to the entrance. For the novel surface test, we tested the goats with a white plastic shower curtain with multicolour spots during the first year, and a blue plastic cover in the second year. The surface was placed on half of pen A, opposite to the entrance, and the other half was covered with straw. For both tests (novel object and surface), the pair of goats was placed in pen $B$ for $5 \mathrm{~min}$, with hay in the feeders. At the end of the $5 \mathrm{~min}$, one experimenter opened the door to pen $A$ (which contained the novel item) and gently encouraged the subject to go inside, while the audience goat remained in pen $B$. The test lasted 5 min during which the subject could interact with the novel item. Then, it was brought back to pen $B$ to serve as an audience goat while the other goat in the pair was tested in pen A. An experimenter stood still while filming the tests from another adjacent pen. She was visible to the subject, but out of reach, which decreased stress linked to the partial isolation in pen A (compared with the isolation test, see below in (2)). All the goats were tested with the novel object test, followed by the novel surface on a different day. 
(2) Sociability. For the isolation test, we placed the pair of goats in pen A for $5 \mathrm{~min}$, with hay in the feeders. At the end of the $5 \mathrm{~min}$, one experimenter took one of the goats out of the stable complex, while the subject was left in pen A for 5 min alone. During this test, all experimenters stayed outside the stable complex, out of view from the subject. The test was filmed by a camera placed on a tripod in the adjacent pen. At the end of the test, we released the subject outside the pen. For the attraction test, we closed the part of the daytime field where the test took place to the other goats using a gate, so that they would be out of sight of the subject. We then led the subject on a rope, along a fence to the starting point where it was held for $30 \mathrm{~s}$. After that, the experimenter walked with the subject in the direction of the other field where the rest of the goats were located, released the subject after $2 \mathrm{~m}$, and continued to walk at a constant speed over a straight $14 \mathrm{~m}$ long path. The path was marked on the ground with white lines every $2 \mathrm{~m}$, in order to calculate the speed of the goat and of the experimenter (as a control; $1.70 \pm 0.19 \mathrm{~m} / \mathrm{s}$ ). When the subject reached the end of the path, the experimenter opened the gate to allow it to join the other goats. The test was filmed with two cameras (one to film the beginning of the path and one to film the end). All the goats were tested with the isolation test, followed by the attraction test on a different day.

\section{Behavioural measures scored}

The behaviour of the goats during the personality tests was scored using CowLog 2.0 (Hänninen \& Pastell, 2009), from the video of the tests (Sony DCR-SX50E camcorder), by the same experimenter for the 2 years of tests. For the tests carried out in pen A (novel object, novel surface and isolation), we scored the behaviour from the time the experimenter closed the door of pen B after exiting the stable complex, and for $5 \mathrm{~min}$. For the attraction test, we scored the behaviour from the time the subject entered the test field until 2 min after the subject passed the gate at the end of the test. All the behaviours scored during the four personality tests are listed, along with their description, in Table A1.

\section{Personality score calculation}

For each personality trait, we calculated a score for each goat using a principal component analysis (PCA). This allowed us to combine all the correlated behaviours in one score, which would be representative of the response of the subjects to the tests (McGregor,1992). The procedure was as follows: all the behavioural data for the two tests of the first year (2011) that we scored to assess a given personality trait (Table A1) were included in the PCA (one PCA per personality trait). Then, in order to be able to compare the 2 years, we calculated the principal component (PC) scores for the second year (2012) by projecting the data of 2012 onto the PC generated by the 2011 PCA (function predict; R software, R Development Core Team, 2014). After verifying consistency between years (see below Consistency over time), the scores of the most relevant PC were averaged over the 2 years (2011 and 2012) to obtain one personality score for each goat.

The PCA performed on the exploration/avoidance data generated five PCs with an eigenvalue greater than 1 (Kaiser's criterion; Table A2), which together explained $77 \%$ of the variance in the original data set. According to the loadings of the behaviours on the PCs (Table A2), the first PC (PC1) reflected exploration/avoidance well across both tests (novel object and novel surface; i.e. goats that were highly explorative or avoided the novel item across both tests). All the behaviours scored during the novel object test, along with three behaviours from the novel surface test (Latency Step on Surface, Time spent on Surface Four Legs and Step On, see Table A1 for definitions), were highly correlated with this PC (Table A2). Highly positive PC1 scores indicated goats that had a strong first reaction to the novel object (i.e. did not enter the pen immediately or had to be led inside) spent a long time staring at the object, took a long time to step in the half of the pen where the object was situated (object's half), took a long time to step on the surface, and did not spend much time in the object's half or with four legs on the surface. These goats also took a long time to smell and touch the object and spent a short time smelling and touching it (if they 
ever did). Most of them did not touch or smell the object, or stepped on the surface at all (Table A2). PC1 scores were thus selected as exploration/avoidance scores for each goat, with highly positive scores indicating goats that avoided/did not explore the novel item much (avoidance scores; Table 1).

The PCA performed on the sociability data generated two PCs with an eigenvalue greater than 1 (Kaiser's criterion; Table A2), which together explained $68 \%$ of the variance in the original data set. According to the loadings of the behaviours on the PCs (Table A2), the second PC (PC2), but not the first, reflected sociability well across both tests (attraction and isolation; i.e. goats that were highly social across both tests, going back quickly to other goats during the attraction test and reacting strongly to the isolation). Three behaviours scored during the attraction test (Time Start-End, Relative Speed and After Gate), as well as three behaviours scored during the isolation test (Time Feed, Locomotion and Calls; see Table A1 for definitions), were highly correlated with PC2 (Table A2). Highly positive PC2 scores indicated goats that went quickly from the starting line to the last line, moved faster than the experimenter (i.e. forward), and went back quickly to the other goats after passing the gate during the attraction test. These goats also did not spend much time feeding, and moved and called a lot during the isolation test (Table A2). By contrast, highly positive PC1 scores corresponded to similar behavioural reactions to the attraction test as for PC2, but for goats that fed for a long time, with a short latency and did not move much during the isolation test, which reflected goats that did not react strongly to the isolation (Table A2). For this reason, we kept the PC2 scores as sociability scores for each goat, with highly positive scores indicating highly social goats in both tests (sociability scores; Table 1).

\section{Consistency over time}

Personality traits are behaviours that should be consistent not only across situations, but also over time (Réale et al., 2007). To verify that the personality scores that we obtained were repeatable over time, we calculated Kendall rank correlations between the scores of the selected PC for 2011 and 2012. For both personality traits, the scores were marginally significantly correlated between the 2 years (Kendall rank correlation: exploration/avoidance (PC1): tau $=0.28, N=25$ goats, $P=0.053$; sociability $(P C 2)$ : tau = $0.30, N=23$ goats, $P=0.051)$. This indicates that the scores tended to be consistent, even over such a long period of time (14-16 months later).

Additionally, we tested whether personality scores were affected by factors other than individuality, such as the presence of horns, age, sex and breed of the goats (Table 1). To this aim, we carried out linear mixed-effects models (LMM; one model for each personality trait; Ime function, nlme library in R software) including the PC scores calculated for both years as a dependent variable, and the presence of horns (coded as $0=$ no horns; 1 = horns), the age, sex and breed of the goats as fixed effects. We also included the identity of the goats as a random effect (two values per goats, for 2011 and 2012). These models showed that the avoidance scores were not affected by any of the factors (LMM, $N=25$ goats: horns: $F_{1,15}=0.48, P=0.50$; age: $F_{1,24}=0.20, P=0.66$; sex: $F_{1,15}=0.05, P=0.83$; breed: $F_{7,15}=1.66, P=$ 0.19). Similarly, sociability scores were not affected by any of the factors (LMM, $N=23$ goats: horns: $F_{1,13}$ $=0.79, P=0.39$; age: $F_{1,22}=1.91, P=0.18$; sex: $F_{1,13}=0.84, P=0.38$; breed: $F_{7,13}=2.01, P=0.13$ ).

For each personality trait, because PC scores were correlated between years (marginally significant), we averaged the PC scores calculated for 2011 and 2012 to obtain one personality score for each goat (Table 1). Three of the 28 goats died from old age between 2011 and 2012 and thus could not be tested during the second year. Because personality scores were averaged over the 2 years, no scores were calculated for these goats. Two goats showed signs of stress during the first habituation to the attraction test. They were thus not tested further and their sociability scores could not be calculated. In total, we were able to assess the personality trait 'exploration/avoidance' in 25 goats, and the personality trait 'sociability' in 23 goats (for 16 of which we measured their physiology while free-ranging; Table 1). 
Table A1. Behaviours scored during the personality tests and their description

\begin{tabular}{|c|c|c|c|}
\hline Trait & Test & Behaviour & Description \\
\hline \multirow[t]{20}{*}{$\begin{array}{l}\text { Exploration/ } \\
\text { avoidance }\end{array}$} & \multirow[t]{10}{*}{$\begin{array}{l}\text { Novel } \\
\text { Object }\end{array}$} & First reaction Object & $\begin{array}{l}\text { First reaction to the object when entering pen A (scored as } 0 \text { : smells or touch the } \\
\text { object with nose directly when entering; } 1 \text { : looks at the object but does not } \\
\text { touch; 2: does not enter pen A spontaneously, has to be led by the } \\
\text { experimenter) }\end{array}$ \\
\hline & & Time Stare at Object & Time spent looking at the object from a distance, with ears pointed in its direction \\
\hline & & Latency Object Half & Latency to step in the half of pen A where the object is ${ }^{\star}$ \\
\hline & & Time in Object Half & Time spent in the half of pen A where the object is \\
\hline & & Latency Smell Object & $\begin{array}{l}\text { Latency to smell the object (i.e. without touching, muzzle at 1-10 cm from the } \\
\text { object) }\end{array}$ \\
\hline & & Time Smell Object & $\begin{array}{l}\text { Time spent smelling the object (i.e. without touching, muzzle at 1-10 } \mathrm{cm} \text { from the } \\
\text { object) }\end{array}$ \\
\hline & & Latency Touch Object & Latency to touch the object (pushing with nose, nibbling or licking the object)* \\
\hline & & Time Touch Object & Time spent touching the object (pushing with nose, nibbling or licking the object) \\
\hline & & Latency Smell/Touch Object & Latency to smell or touch the object (i.e. shortest latency)* \\
\hline & & Touch/Smell & $\begin{array}{l}\text { Occurrence of smelling or touching the object during the test (scored as 0: does } \\
\text { not smell/touch; 1: does smell/touch) }\end{array}$ \\
\hline & \multirow[t]{10}{*}{$\begin{array}{l}\text { Novel } \\
\text { Surface }\end{array}$} & First reaction Surface & $\begin{array}{l}\text { First reaction to the surface item when entering pen A; (scored as } 0 \text { : smells or } \\
\text { touches the surface with nose directly when entering; } 1 \text { : looks at the surface } \\
\text { but does not touch; 2: does not enter pen A spontaneously, has to be led by } \\
\text { the experimenter) }\end{array}$ \\
\hline & & Time Stare at Surface & Time spent looking at the surface from a distance, with ears pointed in its direction \\
\hline & & Latency Step on Surface & Latency to step on the surface* \\
\hline & & $\begin{array}{l}\text { Time spent on Surface Four } \\
\text { Legs }\end{array}$ & Time spent with the four legs on the surface \\
\hline & & $\begin{array}{l}\text { Time spent on Surface 1-3 } \\
\text { Legs }\end{array}$ & Time spent with one to three legs on the surface \\
\hline & & Latency Smell Surface & $\begin{array}{l}\text { Latency to smell the surface (i.e. without touching, muzzle at } 1-10 \mathrm{~cm} \text { from the } \\
\text { surface)* }\end{array}$ \\
\hline & & Time Smell Surface & $\begin{array}{l}\text { Time spent smelling the surface (i.e. without touching, muzzle at 1-10 } \mathrm{cm} \text { from the } \\
\text { surface) }\end{array}$ \\
\hline & & Latency Touch Surface & Latency to touch the surface (pushing with nose, nibbling or licking the surface)* \\
\hline & & Time Touch Surface & $\begin{array}{l}\text { Time spent touching the surface (pushing with nose, nibbling or licking the } \\
\text { surface) }\end{array}$ \\
\hline & & Step On & $\begin{array}{l}\text { Occurrence of stepping on the surface during the test (scored as 0: does not step } \\
\text { on; 1: does step on) }\end{array}$ \\
\hline \multirow[t]{9}{*}{ Sociability } & \multirow[t]{5}{*}{ Attraction } & Willingness & $\begin{array}{l}\text { Willingness to go with the experimenter to the starting point (scored as } 0 \text { : willing, } \\
\text { does not stop; } 1 \text { : stops sometimes; } 2 \text { : does not walk spontaneously, has to be } \\
\text { pulled by the experimenter) }\end{array}$ \\
\hline & & Time Start-End & Time to go from the starting line to the last line \\
\hline & & Pace & Pace used by the goats on the path (scored as 0: walk; 1 : trot; 2 : canter) \\
\hline & & Relative Speed & $\begin{array}{l}\text { Speed of the goats relative to the speed of the experimenter, calculated as goat } \\
\text { speed minus experimenter speed }\end{array}$ \\
\hline & & After Gate & $\begin{array}{l}\text { Behaviour of the goat after passing the gate (scored as } 0 \text { : stays around the gate; } \\
\text { 1: walks back slowly to the other goats; } 2 \text { : trots/canters back to the other } \\
\text { goats) }\end{array}$ \\
\hline & \multirow[t]{4}{*}{ Isolation } & Latency Feed & Latency to start feeding on the hay in the feeder* \\
\hline & & Time Feed & Time spent feeding on the hay in the feeder \\
\hline & & Locomotion & Time spent moving \\
\hline & & Calls & Number of calls \\
\hline
\end{tabular}

* If this behaviour was not performed, a latency of $300 \mathrm{~s}$ (total test duration) was attributed. 
Table A2. Factor loadings of the measured behavioural parameters on the principal components with an eigenvalue greater than one.

\begin{tabular}{|c|c|c|c|c|c|c|c|}
\hline Trait & Test & Behaviour & PC1 & PC2 & PC3 & PC4 & PC5 \\
\hline \multirow[t]{22}{*}{ Exploration/avoidance } & \multirow[t]{10}{*}{ Novel Object } & First reaction Object & 0.51 & 0.15 & -0.23 & 0.53 & -0.41 \\
\hline & & Time Stare at Object & 0.64 & -0.13 & -0.23 & 0.12 & -0.46 \\
\hline & & Latency Object Half & 0.62 & -0.62 & -0.16 & -0.07 & 0.10 \\
\hline & & Time in Object Half & -0.73 & 0.12 & -0.25 & 0.50 & 0.19 \\
\hline & & Latency Smell Object & 0.64 & -0.41 & 0.08 & 0.39 & 0.20 \\
\hline & & Time Smell Object & -0.58 & -0.03 & -0.56 & -0.21 & 0.21 \\
\hline & & Latency Touch Object & 0.77 & -0.22 & -0.07 & -0.16 & 0.20 \\
\hline & & Time Touch Object & -0.73 & -0.09 & -0.40 & 0.31 & 0.03 \\
\hline & & Latency Smell/Touch Object & 0.81 & -0.45 & -0.09 & 0.08 & 0.24 \\
\hline & & Touch/Smell & -0.70 & 0.54 & 0.08 & -0.23 & -0.15 \\
\hline & \multirow[t]{12}{*}{ Novel Surface } & First reaction Surface & 0.43 & 0.50 & -0.34 & 0.37 & -0.31 \\
\hline & & Time Stare at Surface & 0.45 & 0.28 & -0.14 & -0.36 & -0.06 \\
\hline & & Latency Step on Surface & 0.61 & 0.63 & -0.26 & -0.15 & 0.21 \\
\hline & & Time spent on Surface Four Legs & -0.65 & -0.34 & -0.15 & 0.21 & 0.09 \\
\hline & & Time spent on Surface 1-3 Legs & -0.22 & -0.61 & 0.52 & -0.12 & -0.41 \\
\hline & & Latency Smell Surface & -0.03 & 0.24 & 0.68 & 0.32 & 0.27 \\
\hline & & Time Smell Surface & -0.36 & -0.44 & -0.42 & -0.34 & -0.32 \\
\hline & & Latency Touch Surface & 0.21 & 0.75 & 0.36 & -0.02 & -0.25 \\
\hline & & Time Touch Surface & 0.23 & -0.75 & 0.00 & -0.03 & -0.05 \\
\hline & & Step On & -0.55 & -0.69 & 0.23 & 0.12 & -0.19 \\
\hline & & Eigenvalue & 2.52 & 2.05 & 1.42 & 1.23 & 1.11 \\
\hline & & Cumulative \% variance & 32 & 53 & 63 & 70 & 77 \\
\hline \multirow[t]{11}{*}{ Sociability } & \multirow[t]{5}{*}{ Attraction } & Willingness & 0.48 & 0.36 & & & \\
\hline & & Time Start-End & -0.67 & -0.59 & & & \\
\hline & & Pace & 0.90 & 0.22 & & & \\
\hline & & Relative Speed & 0.63 & 0.62 & & & \\
\hline & & After Gate & 0.32 & 0.65 & & & \\
\hline & \multirow[t]{6}{*}{ Isolation } & Latency Feed & -0.73 & 0.48 & & & \\
\hline & & Time Feed & 0.71 & -0.56 & & & \\
\hline & & Locomotion & -0.61 & 0.56 & & & \\
\hline & & Calls & -0.45 & 0.60 & & & \\
\hline & & Eigenvalue & 1.90 & 1.60 & & & \\
\hline & & Cumulative \% variance & 40 & 68 & & & \\
\hline
\end{tabular}

Bold types indicate the heaviest factor loadings $(|r|>0.50)$. Eigenvalues and cumulative explained variances are given. PC1 scores were kept as exploration/avoidance scores and PC2 as sociability scores. 